\title{
Suppression of tumorigenesis by human mesenchymal stem cells in a hepatoma model
}

Ling Qiao ${ }^{1}$, Zhili $\mathrm{Xu}^{2}$, Tiejun Zhao ${ }^{2}$, Zhigang Zhao ${ }^{3}$, Mingxia $\mathrm{Shi}^{3}$, Robert C Zhao ${ }^{3}$, Lihong Ye ${ }^{1}$, Xiaodong Zhang $^{2}$

${ }^{1}$ Department of Biochemistry, College of Life Sciences, Nankai University, Tianjin 300071, China; ${ }^{2}$ Department of Cancer Research, Institute for Molecular Biology, College of Life Sciences, Nankai University, 94 Weijin Road, Tianjin 300071, China: ${ }^{3}$ Department of Cell Biology, Centre of Excellence in Tissue Engineering, Institute of Basic Medical Sciences and School of Basic Medicine, Chinese Academy of Medical Sciences and Peking Union Medical College, Beijing 100073, China

Human mesenchymal stem cells (hMSCs) can home to tumor sites and inhibit the growth of tumor cells. Little is known about the underlying molecular mechanisms that link hMSCs to the targeted inhibition of tumor cells. In this study, we investigated the effects of hMSCs on two human hepatoma cell lines (H7402 and HepG2) using an animal transplantation model, a co-culture system and conditioned media from hMSCs. Animal transplantation studies showed that the latent time for tumor formation was prolonged and that the tumor size was smaller when SCID mice were injected with $\mathrm{H} 7402$ cells and an equal number of Z3 hMSCs. When co-cultured with Z3 cells, $\mathrm{H} 7402$ cell proliferation decreased, apoptosis increased, and the expression of Bcl-2, c-Myc, proliferating cell nuclear antigen (PCNA) and survivin was downregulated. After treatment with conditioned media derived from Z3 hMSC cultures, H4702 cells showed decreased colony-forming ability and decreased proliferation. Immunoblot analysis showed that $\beta$-catenin, Bcl-2, c-Myc, PCNA and survivin expression was downregulated in H7402 and HepG2 cells. Taken together, our findings demonstrate that hMSCs inhibit the malignant phenotypes of the $\mathbf{H 7 4 0 2}$ and HepG2 human liver cancer cell lines, which include proliferation, colony-forming ability and oncogene expression both in vitro and in vivo. Furthermore, our studies provide evidence that the Wnt signaling pathway may have a role in hMSC-mediated targeting and tumor cell inhibition.

Keywords: Mesenchymal stem cells, hepatoma, Wnt signaling, $\beta$-catenin

Cell Research (2008) 18:500-507. doi: 10.1038/cr.2008.40; published online 25 March 2008

\section{Introduction}

Mesenchymal stem cells (MSCs) have been identified as a bone marrow-derived cell population that can differentiate into mesodermal cell lineages that are easily isolated and propagated in vitro. MSCs can differentiate into a number of mesodermal cell lineages, including bone, cartilage, stroma, adipose, connective tissue, muscle and

Correspondence: Xiaodong Zhang ${ }^{\mathrm{a}}$, Lihong $\mathrm{Ye}^{\mathrm{b}}$, Robert C Zhao

${ }^{a}$ Tel: +86-22-23506830; Fax: +86-22-23501385

E-mail: zhangxd@nankai.edu.cn

${ }^{\text {b}}$ Tel: +86-22-23501385; Fax: +86-22-23501385

E-mail: yelihong@nankai.edu.cn

'Tel: +86-10-65125311; Fax: +86-10-65125311

E-mail: chunhuaz@public.tpt.tj.cn

Received 16 February 2007; revised 15 June 2007; accepted 7 November 2007; published online 25 March 2008 tendon. Therefore, human MSCs (hMSCs) that maintain their capacity for self-renewal ability contribute to a wide variety of endogenous organ and tissue repair $[1,2]$. In this rapidly expanding field, more and more attention has been paid to the relationship between stem cells and tumor cells. Growing evidence shows that hMSCs home to sites of tumorigenesis, where they inhibit tumor cell function. For example, hMSCs are recruited with high tumor specificity to gliomas in the brain, and they prolong the survival of tumor-bearing animals [3]. The stem cell microenvironment has an essential role in preventing carcinogenesis by providing signals to inhibit proliferation and to promote differentiation [4]. Human MSCs home to sites of Kaposi's sarcoma, and potently inhibit tumor growth in vivo by downregulating Akt activity in tumor cells that are cultured with hMSCs prior to transplantation in animal tumor models [5]. Furthermore, tumor cells may secrete 
proteins that can activate signaling pathways that facilitate hMSC migration to the tumor site. Gene expression profiling studies of rat MSCs showed that 104 transcripts were upregulated following in vitro exposure to conditioned media from C85 human colorectal cancer cells. Increased stromal cell-derived factor-1 (SDF-1) production by MSCs acts in an autocrine manner and is required for migratory responses to tumor cells $[6,7]$.

Previous studies have shown that hematopoietic stem cell transplantation can have tumor-inhibitory effects in patients with solid tumors, as well as anti-tumor effects in metastatic breast, kidney, ovarian, prostate and pancreatic cancers [8-11]. MSCs have received much attention in the field of stem cell transplantation because they not only support hematopoiesis, but also exhibit a profound immunosuppressive activity that targets mainly T-cell proliferation [12]. Emerging evidence has demonstrated that MSCs may serve as vehicles for the transfer of genetic material. Gene modification of MSCs with therapeutic cytokines is a useful therapeutic tool for treating malignant brain neoplasms. The ability of MSCs to migrate to a specific tumor site where they become activated suggests that they may be useful in cell replacement and gene therapies [13-15]. A detailed analysis of the relationship between tumor cells and MSCs will undoubtedly lead to a new era of both basic research and clinical therapy. However, little is known about the underlying molecular mechanisms that link hMSCs to the tumor microenvironment or about how hMSCs regulate tumor cell phenotypes.

In one of our previous studies, we found that conditioned media from hMSCs were able to inhibit the proliferation of

Table 1 Transplantation in SCID mice inoculated with H7402/Z3 cells

\begin{tabular}{lccc}
\hline \multicolumn{1}{c}{ Groups } & $\begin{array}{c}\text { Number of mice } \\
\text { with tumor } \\
\text { formation }(n=5)\end{array}$ & $\begin{array}{c}\text { Average } \\
\text { volume }\left(\mathrm{cm}^{3}\right)\end{array}$ & $\begin{array}{c}\text { Killed } \\
\text { on day }\end{array}$ \\
\hline $\mathrm{H} 7402+\mathrm{Z} 3$ & 4 & $1.7^{* *}$ & 70 \\
$\mathrm{H} 7402+\mathrm{L}-\mathrm{O} 2$ & 5 & 3.4 & 70 \\
$\mathrm{H} 7402$ & 5 & 3.2 & 70 \\
Z3 & 0 & 0 & 70 \\
L-O2 & 0 & 0 & 70 \\
\hline
\end{tabular}

After irradiation, both H7402 $\left(1 \times 10^{7}\right)$ and Z3 cells $\left(1 \times 10^{7}\right)$ cells or both $\mathrm{H} 7402\left(1 \times 10^{7}\right)$ cells and L-O2 cells $\left(1 \times 10^{7}\right)$ were mixed and subcutaneously inoculated into the nape region of SCID mice, respectively. Tumor formation, average volume and average weight were significantly different between the test group $(\mathrm{H} 7402+\mathrm{Z} 3)$ and the control groups $(* * P<0.01$, versus controls, respectively, Student's $t$ test).

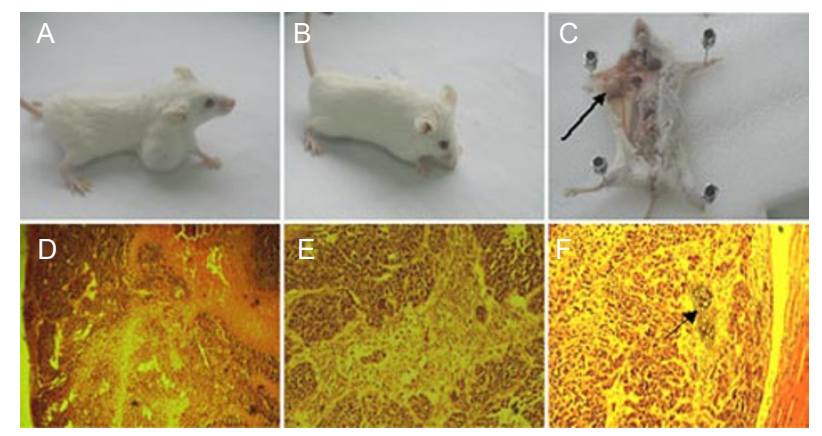

Figure 1 Inhibition of $\mathrm{H} 7402$ cell tumor formation after co-injection with hMSCs in SCID mice. In vivo injection of $\mathrm{H} 7402$ cells in SCID mice led to tumor formation (A). When H7402 cells were co-injected with $Z 3$ cells, one out of five animals did not show any tumors at 70 days (B). When $\mathrm{H} 7402$ cells were co-injected with Z3 cells, smaller tumors formed (arrow). (C). Diffuse necrotic areas were observed in tumor tissues when $\mathrm{H} 7402$ cells were coinjected with Z3 cells (H\&E staining, $40 \times$; D). Fibroblast-like cells were observed within tumor tissues of mice injected with $\mathrm{H} 7402$ and $Z 3$ cells (H\&E staining, $100 \times$; E), and calcified areas (arrow) were observed in the tumor tissues (H\&E staining, $100 \times$; F) when $\mathrm{H} 7402$ cells were co-injected with Z3 cells.

human MCF-7 breast cancer cells in vitro [16]. In this study, we investigated the effects of hMSCs on human hepatoma cells by using conditioned media, a co-culture system and animal transplantation. Here we demonstrate that hMSCs are able to inhibit hepatomas, and that this hMSC-mediated inhibition may involve the Wnt signaling pathway.

\section{Results}

Tumor formation was inhibited by hMSCs in SCID mice

To determine the effect of hMSCs on tumor formation in vivo, SCID mice were injected with human liver cancer cells (H7402 cell line) and an equal number of hMSCs (Z3 cell line) or were injected with $\mathrm{H} 7402$ cells and an equal number of normal human liver cells (L-O2 cell line). Control mice that were transplanted with Z3 cells only $(n=$ 5 mice) or with L-O2 cells only ( $n=5$ mice) did not form tumors, whereas those transplanted with $\mathrm{H} 7402$ cells only $(n=5$ mice $)$ formed tumors (average tumor diameter $=3.2$ $\mathrm{cm}$ on day 70). By contrast, mice injected with both $\mathrm{H} 7402$ cells and L-O2 cells formed detectable tumors within 5-7 days $(n=5$ mice; average tumor diameter $=3.4 \mathrm{~cm}$ on day 70) (Table 1). Mice injected with H7402 and Z3 cells either showed a delay in tumor development or did not develop tumors: 3 mice developed detectable tumors on day 36-37 (average tumor diameter $=1.7 \mathrm{~cm}$ on day 70$), 1$ mouse developed tumors on day 49 (average tumor diameter $=0.4 \mathrm{~cm}$ on day 70) and 1 mouse had not developed any tumors when it was killed on day 70 (Figure 1B and 
1C). Therefore, the data showed that tumor formation was delayed and tumor size was significantly smaller in SCID mice injected with $\mathrm{H} 7402$ and Z3 cells $(P<0.01$, Student's $t$ test). Pathological examination of tumor tissues from the SCID mice injected with $\mathrm{H} 7402$ and Z3 cells showed a wide necrotic area associated with the tumor tissues, the presence of fibroblast-like cells in the tumor tissues and calcification of the tumor area in situ (Figure 1D and 1E). Taken together, these observations suggest that hMSCs may inhibit tumor growth.

Proliferation of hepatoma cells was inhibited by hMSCs in a co-culture system

We next investigated the molecular mechanisms underlying the inhibitory effect of hMSCs on H7402 cells. We tested whether Z3 hMSCs could modulate the malignant phenotypes associated with $\mathrm{H} 7402$ tumor cells in a coculture system. To remove the non-H7402 cells from the co-culture system at a specific time point, we established a stable G418-resistant H7402 cell line, called H7402-P, by selecting for G418-resistant cells after transfection with the empty pcDNA3 vector. We cultured H7402-P cells with Z3 hMSCs or with L-O2 normal human liver cells as negative controls. Before the co-culture experiments, we determined that neither $\mathrm{Z} 3$ nor L-O2 cells could survive when cultured in media containing $300 \mu \mathrm{g} / \mathrm{ml} \mathrm{G} 418$ for 5 days (Figure 2A). Therefore, co-cultures treated with $450 \mu \mathrm{g} / \mathrm{ml} \mathrm{G418}$ for 5 days maintained the H7402-P cell populations, but were completely devoid of Z3 (Figure 2B) or L-O2 cell populations (data not shown). Rates of cell proliferation in the co-culture experiments were determined using flow cytometry analysis. The proliferation index (PI) decreased from $21.2 \%$ to $16.7 \%$ when H7402-P cells were cultured with Z3 cells, whereas the apoptotic rate increased from $4.1 \%$ to $16.9 \%$ when $\mathrm{H} 7402$ cells were cultured with Z3 cells $\left(P<0.01, \chi^{2}\right.$ test, Figure $\left.2 C\right)$. The decrease in proliferation and increase in apoptosis were associated with downregulation of Bcl-2, c-Myc, proliferating cell nuclear antigen (PCNA) and survivin protein levels in the H7402-P cells cultured with Z3 cells (Figure 2D).
A

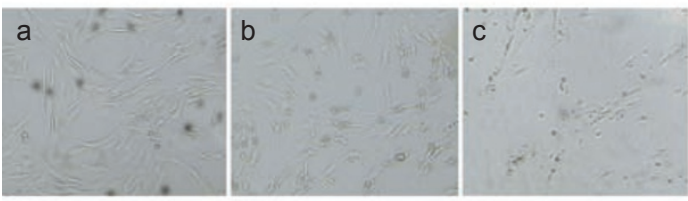

C
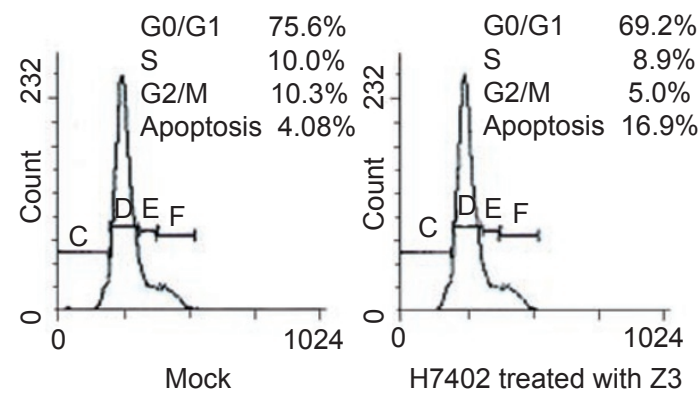

B

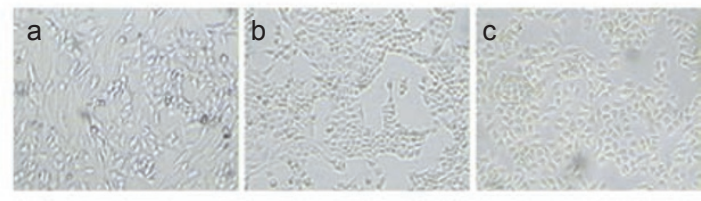

D

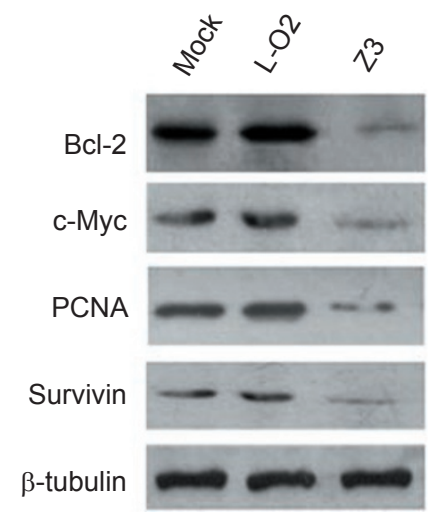

Figure 2 Effect of Z3 hMSCs on H7402 cells in a co-culture system. Results of a G418 toxicity test showed a normal morphology of Z3 cells in the absence of G418 (Aa), after 2 days in G418-containing medium (Ab) and after 5 days in G418-containing medium $(\mathbf{A c}, \times 100)$. Cell morphology of cultures of Z3 and H4702-P cells grown in the absence of G418 (Ba), after 3 days in medium containing $450 \mu \mathrm{g} / \mathrm{ml}$ G418 (Bb), and after 5 days in medium containing $450 \mu \mathrm{g} / \mathrm{ml} \mathrm{G} 418$ (Bc). Images were acquired using a $100 \times$ objective lens. Flow cytometric analyses showed that $\mathrm{H} 7402-\mathrm{P}$ cell proliferation was inhibited when co-cultured with $\mathrm{Z3}$ cells. The PI decreased from $21.2 \%$ to $16.7 \%$, whereas the apoptotic rate increased from $4.1 \%$ to $16.9 \%$ in $\mathrm{H} 7402-\mathrm{P}$ cells co-cultured with $\mathrm{Z} 3$ stem cells relative to $\mathrm{H} 7402-\mathrm{P}$ cells co-cultured with $\mathrm{L}-\mathrm{O} 2$ control cells (C, results were representative of three independent experiments). Immunoblot analysis showed that Bcl-2, c-Myc, PCNA and survivin expression was downregulated in $\mathrm{H} 7402-\mathrm{P}$ cells co-cultured with $\mathrm{Z} 3$ stem cells relative to $\mathrm{H} 7402-\mathrm{P}$ cells co-cultured with L-O2 cells (D, results were representative of three independent experiments). 
Proliferation of hepatoma cells was inhibited by conditioned media derived from hMSC cultures

The surrounding tissue microenvironment has an important role in tumorigenesis. In order to determine whether the cultured hMSCs release soluble factors that can inhibit tumor cell growth, we tested whether conditioned media from Z3 cell cultures affected the ability of $\mathrm{H} 7402$ cells to form colonies. We found that treatment of $\mathrm{H} 7402$ cells with $\mathrm{Z} 3$ conditioned media led to a significant reduction in the number of $\mathrm{H} 7402$ colony-forming units relative to control cells $(P<0.01$, Student's $t$ test, Figure 3A). We also determined the proliferation of $\mathrm{H} 7402$ cells treated with $\mathrm{Z} 3$ conditioned media using bromodeoxyuridine (BrdU) incorporation assay. Control H7402 cells showed $38.2 \%$ BrdU-positive cells, whereas $\mathrm{H} 7402$ cells treated with Z3 conditioned media showed 29.2\% BrdU-positive cells $(P<0.01$ versus control, Student's $t$ test, Figure 3B). The results of these experiments show that treatment with conditioned media from Z3 cells leads to a significantly lower percentage of $\mathrm{S}$ phase $\mathrm{H} 7402$ cells relative to treatment with control media (Figure 3B). The histogram in Figure $3 \mathrm{C}$ shows the positive rates of BrdU-positive cells (**P<0.01, Student's $t$ test). Similar results were obtained in three independent experiments.

Downregulation of Wnt signaling in tumor cells by conditioned media from hMSC cultures

Since canonical Wnt signaling regulates the proliferation of tumor cells and various stem cells [17, 18], we propose that the Wnt signal transduction pathway might be involved in governing the inhibitory effect on tumor cells mediated by hMSCs. Immunoblot analysis showed that treatment of H7402 or HepG2 liver cancer cell lines with Z3 conditioned media resulted in the downregulation of $\beta$-catenin, $\mathrm{Bcl}-2$, c-Myc, PCNA and survivin (Figure 4A). However, L-O2 conditioned media failed to downregulate the expression
A

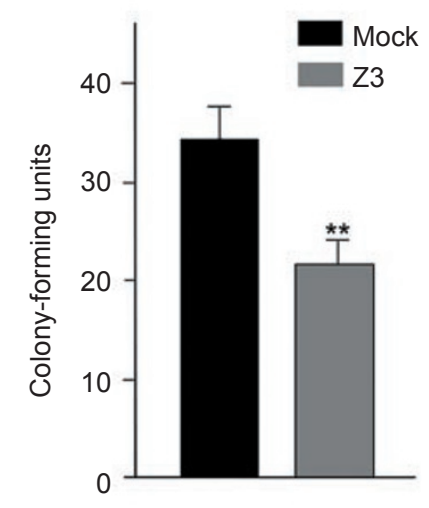

B
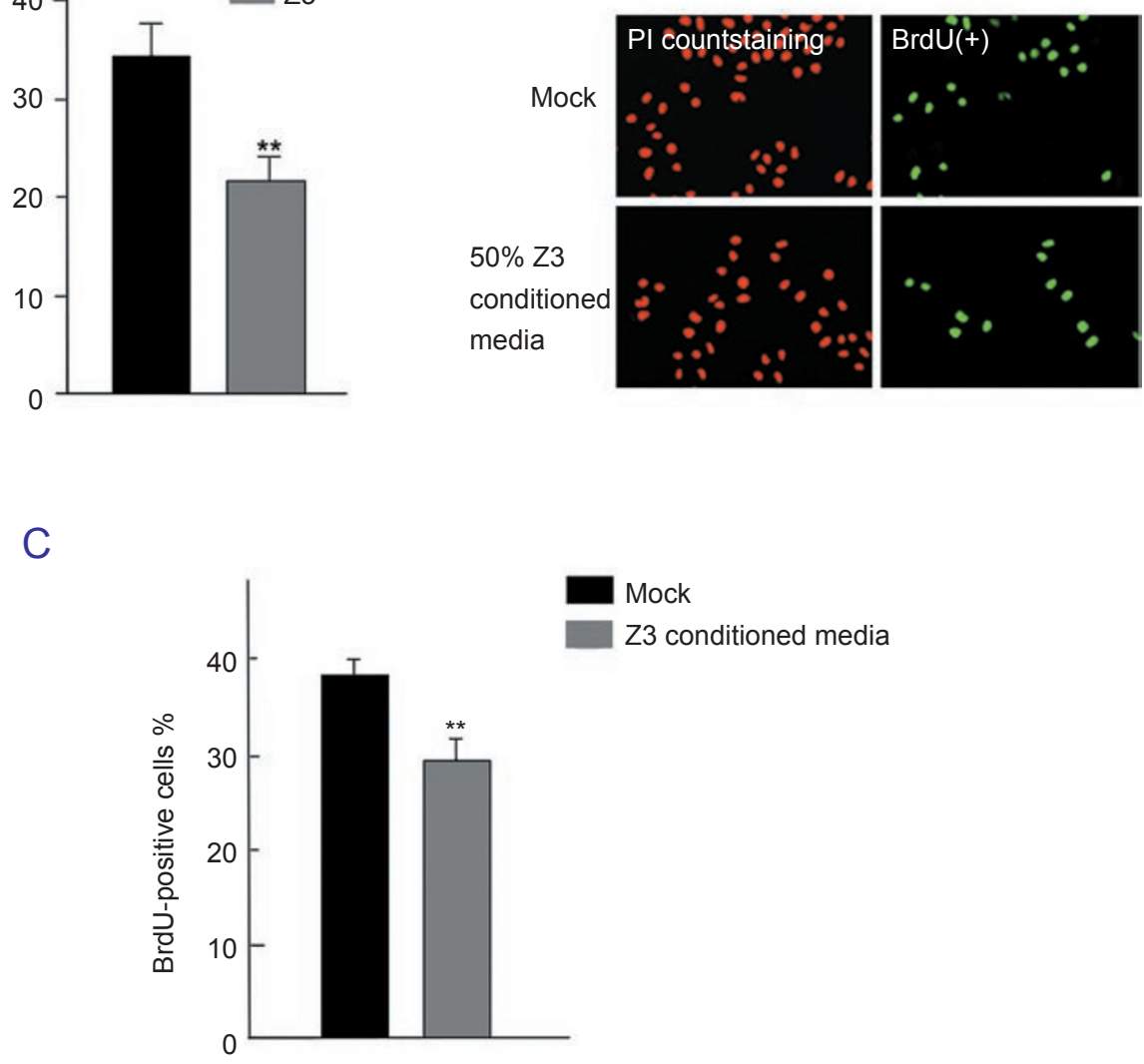

Figure 3 Effect of conditioned media from Z3 cells on $\mathrm{H} 7402$ cell proliferation. There were significantly fewer colony-forming units of $\mathrm{H} 7402$ cells treated with conditioned media from Z3 hMSCs than of control cells ( ${ }^{* *} P<0.01$, Student's $t$ test, A). The proliferation of $\mathrm{H} 7402$ cells treated with conditioned media from Z3 hMSCs was significantly lower than that of control cells, as determined by a BrdU incorporation assay (B). The histogram shows the positive rates of BrdU-positive cells $\left({ }^{* *} P<0.01\right.$, Student's $t$ test, C). Similar results were obtained in three independent experiments. 
A

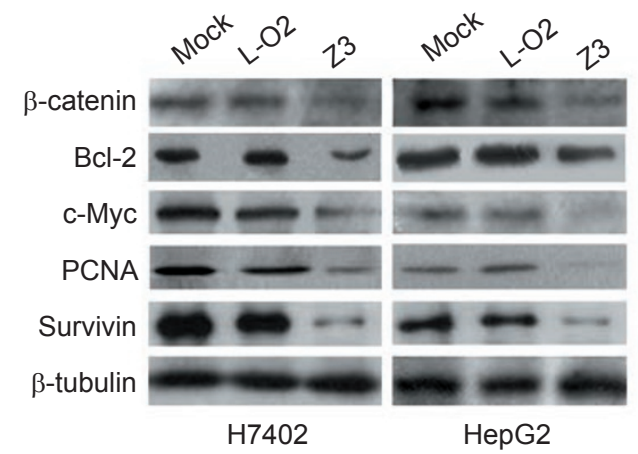

B
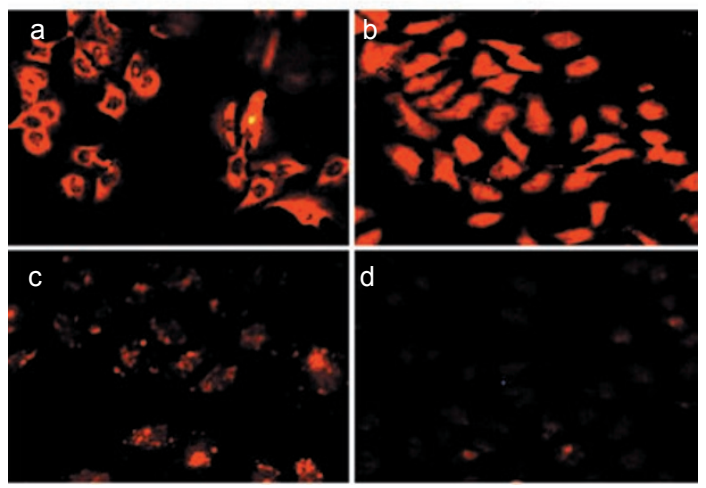

Figure 4 Effect of conditioned media from Z3 cells on the Wnt signaling pathway of $\mathrm{H} 7402$ and HepG2 cells. Immunoblot analysis showed that the treatment of $\mathrm{H} 7402$ or HepG2 cells with $10 \%$ conditioned media from $\mathrm{Z} 3 \mathrm{hMSC}$ cultures leads to the downregulation of $\beta$-catenin, $\mathrm{Bcl}-2, \mathrm{c}-\mathrm{Myc}, \mathrm{PCNA}$ or survivin expression. However, the treatment of $\mathrm{H} 7402$ or $\mathrm{HepG} 2$ cells with $10 \%$ conditioned media from L-O2 cultures fails to downregulate the expression of these proteins (A). Indirect immunofluorescence staining demonstrated that cytoplasmic and nuclear $\beta$-catenin labeling in $\mathrm{H} 7402$ cells was reduced following treatment with $10 \% \mathrm{Z} 3$ conditioned media (B, $100 \times$ objective). $\beta$-Catenin positive labeling was shown in the cytoplasm (a) or nuclei (b) of $\mathrm{H} 7402$ cells. The positive labeling of $\beta$-catenin was reduced by treatment with $10 \%$ Z3 conditioned media (c). The positive labeling of $\beta$-catenin was not detectable in the $\mathrm{H} 7402$ cells without adding rabbit anti- $\beta$-catenin antibody as a negative control (d). Results shown are representative of three independent experiments.

of $\beta$-catenin, Bcl-2, c-Myc, PCNA or survivin in $\mathrm{H} 7402$ and HepG2 cells (Figure 4A). Furthermore, we examined the cellular localization of $\beta$-catenin through indirect immunofluorescence staining. Treatment of $\mathrm{H} 7402$ cells with $\mathrm{Z} 3$ conditioned media resulted in a decrease in $\beta$-catenin nuclear assembly (Figure 4B). These data are consistent with the hypothesis that soluble factors in conditioned media released from $\mathrm{Z} 3 \mathrm{hMSC}$ cultures inhibit tumor cell proliferation via the Wnt signaling pathway.

\section{Discussion}

Despite their distinct origins, stem cells and tumor cells share many characteristics [7, 19]. In particular, they have similar signaling pathways that regulate self-renewal and differentiation, including the Wnt, Notch, Shh and BMP pathways that determine the diverse developmental fates of cells [17, 18, 20-23]. Therefore, understanding these signaling cascades may provide insights into the molecular mechanisms that underlie tumorigenesis. The Wnt signaling pathway has been widely investigated in recent years. It has an important role in stem cell self-renewal and differentiation, and aberrant activation of the Wnt signaling pathway has been implicated in human tumor progression [24-26]. Expression profiles of Wnt signaling components in MSCs have identified an endogenous canonical Wnt pathway that regulates MSC self-renewal and differentiation programs. Stimulation of hMSCs with Wnt3a results in the accumulation of nuclear $\beta$-catenin and the upregulation of typical Wnt target genes, including cyclin D1 and membrane-type matrix metalloproteinase-1 (MT1-MMP). It has been reported that Dkk-1, a soluble inhibitor of Wnt signaling, could inhibit hMSC proliferation and maintain an undifferentiated phenotype [27, 28]. Furthermore, the canonical Wnt signaling pathway has a critical role in the regulation of proliferation, as well as in the migration/invasion capacity of hMSCs [29]. This has raised the possibility that the tightly regulated self-renewal process that is mediated by Wnt signaling in stem cells and progenitor cells may be subverted in cancer cells to allow malignant proliferation. Cell fates in the developing tumor depend on inductive interactions between neighboring cells. In many cases, these interactions involve secreted proteins of the Wnt family. Wnt proteins, which are members of a proto-oncoprotein family, can promote cell proliferation and transformation when mutated or overexpressed, thereby leading to tumor formation. Wnt signaling regulates genes that are involved in cell metabolism, proliferation, cell-cycle regulation and apoptosis [30, 31]. The PCNA, c-Myc, survivin and Bcl-2 genes are all targets of Wnt signaling [32, 33].

Our data demonstrated the ability of hMSCs to inhibit cancer cell phenotypes in three experimental systems, including an animal transplantation model for tumorigenesis, co-culture experiments and using conditioned media to determine the role of secreted molecules. First, we injected SCID mice with equal numbers of Z3 hMSCs and $\mathrm{H} 7402$ human hepatoma cells: results of these experiments showed that the latent time to tumor formation was prolonged and the tumor size was smaller. In control experiments, L-O2 normal human liver cells failed to inhibit tumorigenesis 
when injected with $\mathrm{H} 7402$ cells in SCID mice. Second, we investigated the effect of hMSCs on tumor cell proliferation and apoptosis in a co-culture system: results of these experiments showed that the PI was lower and the rate of apoptosis was higher in $\mathrm{H} 7402$ cells cultured with Z3 hMSCs. Immunoblot analysis revealed that expression levels of the PCNA, Bcl-2, survivin and c-Myc proteins were all downregulated in $\mathrm{H} 7402$ hepatoma cells that were cultured with Z3 hMSCs, which suggests that hMSCs are able to inhibit $\mathrm{H} 7402$ cell growth. Finally, in order to determine whether soluble factors are involved in this inhibition, we treated human H7402 and HepG2 hepatoma cell lines with conditioned media from $\mathrm{Z} 3$ cells. We found that there were considerably fewer colony-forming units in hepatoma cells treated with conditioned media than in control cells. In addition, the PI of hepatoma cell lines treated with conditioned media from Z3 cell cultures was significantly lower than in control cells. Finally, we characterized some of the molecular events that are associated with hMSC-mediated inhibition of tumor cell phenotypes. Immunoblot analysis showed that $\beta$-catenin, Bcl-2, c-Myc, PCNA and survivin protein levels were downregulated in hepatoma cell lines treated with Z3 conditioned media. Furthermore, treatment with $\mathrm{Z} 3$ conditioned media led to a significant reduction in $\beta$-catenin nuclear assembly (Figure 4B). These data suggest that conditioned media from Z3 cells may inhibit tumor cell phenotypes via the secretion of soluble factors that are involved in the Wnt signaling pathway. Here we show that hMSCs can inhibit the growth of tumor cells in vivo and in vitro. Furthermore, our studies suggest that the Wnt signaling pathway is likely to regulate the inhibitory role of hMSCs. Therefore, modulating the $\mathrm{Wnt} / \beta$-catenin signaling pathway may improve therapeutic strategies that involve the hMSC-mediated targeting of tumor cells.

\section{Materials and Methods}

\section{Cell culture}

The Z3 hMSCs were established from the dermal tissues of a human fetus aborted at 4 months gestation and were immortalized by stable transfection of the pGRN145 plasmid containing the cloned human telomerase reverse transcriptase ( $h T E R T)$ gene. Single-cell clones positive for telomerase activity and hTERT mRNA were selected and expanded. FACScan flow cytometry showed that hTERT (+) cells were positive for CD29, CD44, CD105 and CD166, but were negative for CD31, CD45, CD34, vWF and HLA-DR. Under suitable conditions, hTERT $(+)$ cells can differentiate into multiple cell lineages, including bone, fat and nerve [34]. We cultured Z3 cells in Dulbecco's modified Eagle's medium with low glucose (LDMEM) and Iscove's modified Dulbecco's medium (IMDM) (1:1) supplemented with $10 \%$ fetal calf serum (GIBCO). Human liver cancer cell lines (H7402 [35] and HepG2) and a normal human liver cell line (L-O2) were cultured in RPMI 1640 medium containing $10 \%$ fetal calf serum, $100 \mathrm{U} / \mathrm{ml}$ penicillin, $100 \mathrm{mg} / \mathrm{ml}$ streptomycin and $1 \%$ glutamine.

\section{SCID mouse transplantation}

We obtained SCID mice which were ethical treatment of the animals from the Center of Experimental Animals, Chinese Military Medicine Academy. Mice of age 4-6 weeks were used and kept in pathogen-free conditions as described [36]. Animals were divided into five groups. Groups 1 and 2 consisted of mice that were treated with a mixture of equal numbers of Z3 $\left(1 \times 10^{7}\right)$ and H7402 $(1 \times$ $\left.10^{7}\right)$ cells, or with a mixture of equal numbers of L-O2 $\left(1 \times 10^{7}\right)$ and H7402 $\left(1 \times 10^{7}\right)$ cells; cells were combined and injected subcutaneously into the nape region of SCID mice after irradiation. Groups 3,4 and 5 consisted of mice subcutaneously injected with each cell line alone, including H7402 $\left(1 \times 10^{7}\right)$, Z3 $\left(1 \times 10^{7}\right)$ or L-O2 $\left(1 \times 10^{7}\right)$ cells, respectively. At 70 days post-injection, tumor tissues were fixed in $10 \%$ formaldehyde and processed using standard methods. The sections were stained using hematoxylin and eosin (H\&E) in order to examine the histopathology.

\section{Transfection}

H7402 cells were transfected using Lipofectamine reagent (Invitrogen Corporation, USA) according to the manufacturer's protocol using $2 \mathrm{~g}$ of empty pcDNA3 vector in triplicate. $\mathrm{H} 7402$ cells were treated with $300 \mu \mathrm{g} / \mathrm{ml}$ or $450 \mu \mathrm{g} / \mathrm{ml} \mathrm{G} 418$ (Genview, USA) for 5 days. Using this approach, a stable G418-resistant cell line called H7402-P was established.

\section{Co-culture of stem cells and tumor cells}

To determine the effect of hMSCs on liver tumor cells, we cultured an equal number of Z3 and H7402-P cells or an equal number of L-O2 and H7402-P cells for 3 days. After 3 days, the co-cultured cells were treated with $450 \mu \mathrm{g} / \mathrm{ml} \mathrm{G} 418$ for 5 days to remove the G418-sensitive Z3 or L-O2 cells, followed by flow cytometry and immunoblot analysis.

\section{Flow cytometric analysis}

The PI of H7402-P cells co-cultured with Z3 cells was determined using flow cytometry. Cells were fixed using $70 \%$ ice-cold ethanol, followed by propidium iodine (Sigma, USA) staining $(50 \mu \mathrm{g} / \mathrm{ml})$ in the presence of RNaseA (Sigma, USA) $\left(50 \mathrm{~g} / \mathrm{ml}, 30 \mathrm{~min}, 37^{\circ} \mathrm{C}\right.$ in the dark), and re-suspension in PBS. The PI was calculated according to the formula $\mathrm{PI}=(\mathrm{G} 2 / \mathrm{M}+\mathrm{S}) \div(\mathrm{G} 0 / \mathrm{G} 1+\mathrm{S}+\mathrm{G} 2 / \mathrm{M}) \times 100 \%[37]$.

\section{Treatment with conditioned media}

$\mathrm{Z} 3$ cells and L-O2 cells (as a negative control) were cultured as described above to $100 \%$ confluence. The conditioned media from the $\mathrm{Z} 3$ or L-O2 cells were harvested and stored at $-80{ }^{\circ} \mathrm{C}$ until use. Synchronized $\mathrm{H} 7402$ or $\mathrm{HepG} 2$ cells were pre-treated with a mixture of RPMI 1640 medium containing 10\% fetal calf serum and Z3-conditioned media ( $9: 1$ or $1: 1$ ) for $48-96 \mathrm{~h}$, and the culture media were replaced every $24 \mathrm{~h}$. As a negative control, synchronous $\mathrm{H} 7402$ or HepG2 cells were cultured with RPMI 1640 medium containing 10\% fetal calf serum and L-O2-conditioned media (9:1) for $96 \mathrm{~h}$, and the culture media were replaced every $24 \mathrm{~h}$.

\section{Colony-forming assay}

$\mathrm{H} 7402$ cells at a final concentration of $10^{3}$ cells $/ \mathrm{ml}$ were suspended in RPMI 1640 medium containing 10\% conditioned media from $\mathrm{Z} 3$ cell cultures and $0.3 \%$ low-melting agarose, placed into a 24-well plate and incubated for 2-3 weeks. Mock was used as a control, which was not treated with conditioned media from $\mathrm{Z} 3$ cell 
cultures. Colony-forming units were inspected microscopically using a $40 \times$ objective.

\section{BrdU incorporation assay}

Five-BrdU (from Sigma) was used to label newly synthesized DNA [38]. Briefly, H7402 cells were seeded in a 24-well plate and incubated for $48 \mathrm{~h}$ in a treatment of $50 \% \mathrm{Z} 3$ conditioned medium. $\mathrm{BrdU}(10 \mu \mathrm{mol} / \mathrm{L}$ final concentration) was added, and the cells were re-incubated for an additional $4 \mathrm{~h}$ at $37^{\circ} \mathrm{C}$. BrdU incorporation was detected using a monoclonal antibody against $\operatorname{BrdU}$ (1:300 dilution, $2 \mathrm{~h}$, room temperature, NeoMarkers, USA), followed by incubation with FITC-conjugated goat anti-mouse IgG (1:100 dilution, Sigma, USA) and propidium iodide nuclear counter staining. The results are shown as a ratio of the number of BrdU-positive cells divided by the total number of propidium iodide-positive cells. Three independent experiments were performed.

\section{Immunoblot analysis}

Expression levels of Bcl-2, PCNA, survivin, c-Myc and $\beta$-catenin were examined in $\mathrm{H} 7402$ and HepG2 cells by immunoblot analysis. Co-cultured cells and cells grown in $\mathrm{Z} 3$ or L-O2 conditioned media were re-suspended in lysis buffer at $4{ }^{\circ} \mathrm{C}(62.5 \mathrm{mM}$ Tris- $\mathrm{HCl}, \mathrm{pH} 6.8$, 2\% SDS, 5\% 2-mercaptoethanol, 10\% glycerol), followed by sonication. Proteins were subjected to SDS-PAGE analysis, transferred to nitrocellulose membranes and incubated with primary antibodies against c-Myc (1:1 000 dilution, NeoMarkers, USA), Bcl-2 (1:500 dilution, NeoMarkers, USA), PCNA (1:1 000 dilution, Labvision, USA), survivin (1:1 000 dilution, NeoMarkers, USA) or $\beta$-catenin (1:2 000 dilution, Sigma, USA). Protein bands were detected using an enhanced chemiluminescence reagent (Sigma, USA) following incubation with horse radish peroxidase-conjugated secondary antibodies (1:1 000 dilution, Sigma, USA).

\section{Indirect immunofluorescence staining}

Indirect immunofluorescence staining was used to examine $\beta$-catenin localization in $\mathrm{H} 7402$ cells after 4 days of growth in conditioned media [39]. Cells were fixed at $4{ }^{\circ} \mathrm{C}$ for 20 min using $100 \%$ methanol pre-chilled to $-20{ }^{\circ} \mathrm{C}$, followed by incubation in blocking solution ( $3 \%$ normal goat serum) at room temperature for $20 \mathrm{~min}$. The cells were then incubated for $2 \mathrm{~h}$ at room temperature in PBS containing a rabbit polyclonal antibody that specifically recognizes human $\beta$-catenin (1:100 dilution, Sigma, USA), followed by three washes with PBS containing $0.1 \%$ Tween-20. As a negative control, cells were incubated in PBS without the anti- $\beta$-catenin antibody. Then, the cells were incubated with Cy3-conjugated goat-anti-rabbit IgG (1:100 dilution, Sigma, USA), followed by three washes with PBS/0.1\% Tween-20.

\section{Statistical analysis}

Statistical significance was assessed by comparing mean vales $( \pm$ SD) using the Student's $t$ test for independent groups.

\section{Acknowledgments}

This work was supported by grants from the National Basic Research Program of China (973 Program, No. 2007CB914800 to Xiaodong Zhang), National Natural Science Foundation of China (No. 30570698 to Xiaodong
Zhang) and Tianjin Natural Scientific Foundation (No. 033801211 to Xiaodong Zhang).

\section{References}

1 Pittenger MF, Martin BJ. Mesenchymal stem cells and their potential as cardiac therapeutics. Circ Res 2004; 95:9-20.

2 Wulf GG, Chapuy B, Trumper L. Mesenchymal stem cells from bone marrow. Phenotype, aspects of biology, and clinical perspectives. Med Klin (Munich) 2006; 101:408-413.

3 Nakamizo A, Marini F, Amano T, et al. Human bone marrowderived mesenchymal stem cells in the treatment of gliomas. Cancer Res 2005; 65:3307-3318.

4 Livraghi T, Meloni F, Frosi A. Treatment with stem cell differentiation stage factors of intermediate-advanced hepatocellular carcinoma: an open randomized clinical trial. Oncol Res 2005; 15:399-408.

5 Khakoo AY, Pati S, Anderson SA, et al. Human mesenchymal stem cells exert potent antitumorigenic effects in a model of Kaposi's sarcoma. J Exp Med 2006; 203:1235-1247.

6 Ponte AL, Marais E, Gallay N, et al. The in vitro migration capacity of human bone marrow mesenchymal stem cells: comparison of chemokine and growth factor chemotactic activities. Stem Cells 2007; 25:1737-1745.

7 Menon LG, Picinich S, Koneru R, et al. Differential gene expression associated with migration of mesenchymal stem cells to conditioned medium from tumor cells or bone marrow cells. Stem Cells 2007; 25:520-528.

8 Fagioli F, Berger M, Brach del Prever A, et al. Regression of metastatic osteosarcoma following non-myeloablative stem cell transplantation. A case report. Haematologica 2003; 88: ERC16.

9 Omuro Y, Matsumoto G, Sasaki T, et al. Regression of an unresectable pancreatic tumor following nonmyeloablative allogeneic peripheral-blood stem-cell transplantation. Bone Marrow Transplant 2003; 31:943-945.

10 Renga M, Pedrazzoli P, Siena S. Present results and perspectives of allogeneic non-myeloablative hematopoietic stem cell transplantation for treatment of human solid tumors. Ann Oncol 2003; 14:1177-1184.

11 Ringden O, Le Blanc K. Allogeneic hematopoietic stem cell transplantation: state of the art and new perspectives. APMIS 2005; 113:813-830.

12 Pommey S, Galipeau J. The use of mesenchymal stromal cells in oncology and cell therapy. Bull Cancer 2006; 93:901-907.

13 Hamada H, Kobune M, Nakamura K, et al. Mesenchymal stem cells (MSC) as therapeutic cytoreagents for gene therapy. Cancer Sci 2005; 96:149-156.

14 Yuan X, Hu J, Belladonna ML, et al. Interleukin-23-expressing bone marrow-derived neural stem-like cells exhibit antitumor activity against intracranial glioma. Cancer Res 2006; 66:26302638.

15 Studeny M, Marini FC, Dembinski JL, et al. Mesenchymal stem cells: potential precursors for tumor stroma and targeted-delivery vehicles for anticancer agents. J Natl Cancer Inst 2004; 96:15931603.

16 Qiao L, Xu ZL, Tan X, et al. Investigation of inhibition of Wnt/ $\beta$-catenin pathway in breast cancer cells mediated by Dkk-1 released from human mesenchymal stem cells. Prog Biochem 
Biophys 2007; 34:702-708.

17 Lindvall C, Evans NC, Zylstra CR, et al. The WNT signalling receptor, LRP5, is required for mammary ductal stem cell activity and WNT1-induced tumorigenesis. J Biol Chem 2006; 281:35081-35087.

18 Reya T, Clevers H. Wnt signalling in stem cells and cancer. Nature 2005; 434:843-850.

19 Reya T, Morrison SJ, Clarke MF, et al. Stem cells, cancer, and cancer stem cells. Nature 2001; 414:105-111.

20 Willert K, Jones KA. Wnt signalling: is the party in the nucleus? Genes Dev 2006; 20:1394-1404.

21 Raida M, Heymann AC, Gunther C, et al. Role of bone morphogenetic protein 2 in the crosstalk between endothelial progenitor cells and mesenchymal stem cells. Int J Mol Med 2006; 18:735739.

22 Androutsellis-Theotokis A, Leker RR, Soldner F, et al. Notch signalling regulates stem cell numbers in vitro and in vivo. Nature 2006; 442:823-826.

23 Miele L, Miao H, Nickoloff BJ. NOTCH signalling as a novel cancer therapeutic target. Curr Cancer Drug Targets 2006; 6:313323.

24 Gaspar C, Fodde R. APC dosage effects in tumorigenesis and stem cell differentiation. Int J Dev Biol 2004; 48:377-386.

25 Chen G, Shukeir N, Potti A, et al. Up-regulation of Wnt-1 and beta-catenin production in patients with advanced metastatic prostate carcinoma: potential pathogenetic and prognostic implications. Cancer 2004; 101:1345-1356.

26 Moon RT, Kohn AD, Ferrari GV De, et al. WNT and beta-catenin signalling: diseases and therapies. Nat Rev Genet 2004; 5:691701.

27 Etheridgea SL, Spencera GJ, Heathb DJ, et al. Expression profiling and functional analysis of Wnt signalling mechanisms in mesenchymal stem cells. Stem Cells 2004; 22:849-860.

28 Gregory CA, Singh H, Perry AS, et al. The Wnt signalling inhibitor Dickkopf-1 is required for reentry into the cell cycle of human adult stem cells from bone marrow. J Biol Chem 2003; 278:28067-28078.
29 Neth P, Ciccarella M, Egea V, et al. Wnt signalling regulates the invasion capacity of human mesenchymal stem cells. Stem Cells 2006; 24:1892-1903.

30 Yang F, Zeng Q, Yu G, et al. Wnt/beta-catenin signalling inhibits death receptor-mediated apoptosis and promotes invasive growth of HNSCC. Cell Signal 2006; 18:679-687.

31 Baek SH, Kioussi C, Briata P, et al. Regulated subset of G1 growth-control genes in response to derepression by the Wnt pathway. Proc Natl Acad Sci USA 2003; 100:3245-3250.

32 Joubert A, Bianchi P, Maritz C, et al. Influence of prostaglandin $\mathrm{A} 2$ on Bax, Bcl-2 and PCNA expression in MCF-7 cells. Biomed Res 2006; 27:157-162.

33 Muncan V, Sansom OJ, Tertoolen L, et al. Rapid loss of intestinal crypts upon conditional deletion of the Wnt/Tcf-4 target gene c-Myc. Mol Cell Biol 2006; 26:8418-8426.

34 Zhao Z, Liao L, Cao Y, et al. Establishment and properties of fetal dermis-derived mesenchymal stem cell lines: plasticity in vitro and hematopoietic protection in vivo. Bone Marrow Transplant 2005; 36:355-365.

35 Liu B, Liu Y, Chen J, et al. CARP is a novel caspase recruitment domain containing pro-apoptotic protein. Biochem Biophys Res Commun 2002; 24:1396-1404.

36 Prockop DJ, Gregory CA, Spees JL. One strategy for cell and gene therapy: harnessing the power of adult stem cells to repair tissues. Proc Natl Acad Sci USA 2003; 100:11917-11923.

37 Plas E, Carroll VA, Jilch R, et al. Variations of components of the plasminogen activation system with the cell cycle in benign prostate tissue and prostate cancer. Cytometry 2001; 46:184189.

38 Lengronne A, Pasero P, Bensimon A, Schwob E. Monitoring S phase progression globally and locally using BrdU incorporation in TK+ yeast strains. Nucleic Acids Res 2001; 29:1433-1442.

39 Kaiser MJ, Tiegs G, Neuhuber WL. Close apposition of dynorphin-positive nerve fibres to lymphocytes in the liver suggests opioidergic neuroimmunomodulation. Histochem Cell Biol 2003; 120:213-221. 